\title{
Experiência, ação e narrativa: reflexões sobre um curso de Hannah Arendt ${ }^{1}$
}

CELSO LAFER

I

O SEU percurso, Hannah Arendt atribuiu grande importância à narra-
tiva e à experiência como meios de alcançar a compreensão das coisas
- compreensão que era para ela uma exigência vital como explicitou na conhecida entrevista de 1964 a Günther Gauss (Arendt, 1994, p.3).

No prefácio a Entre o passado e o futuro, ela realça a importância do significado dos eventos na mente dos que contam a estória por meio da articulação alcançada pela lembrança (Arendt, 1968a, p.6 [1972, p.32]). Uma das epígrafes do capítulo sobre a Ação, em $A$ condição humana, é de Isak Dinesen, escritora que ela muito apreciava e sobre a qual escreveu em Homens em tempos sombrios (Arendt, 1968b, p.95-109 [1987, p.87-98]). Diz a epígrafe: “All sorrows can be borne if you put them in a story or tell a story about them"(Arendt, 1998, p.175 [1981, p.188]).

A epígrafe explicita o poder redentor e esclarecedor da narrativa que Hannah Arendt (1968b, p.21 [1987, p.28]) especificamente realça no seu ensaio sobre Lessing. O significado da narrativa em Hannah Arendt foi objeto de um ensaio pioneiro de Melvyn Hill (1979, p.275-300), de um importante texto de Seyla Benhabib (1994, p.111-37) e de relevantes considerações de Lisa Jane Disch (1996). É também o tema de livro de Julia Kristeva. Nele explora a importância da narração na articulação do pensamento político de Hannah Arendt, discutindo os modos como, na vida humana, segundo a leitura arendtiana, a ação política é revelada na linguagem da narratividade, seja pela estória seja pela História (Kristeva, 2001, p.13). Em síntese, como observa Leora Y. Bilsky (2001, p.272), narratividade em conjunto com a pluralidade e a natalidade configura as três facetas da ação humana.

O valor epistemológico e existencial da experiência, numa época em que os universais do pensamento se tornaram fugidios, é outro tema forte em Hannah Arendt e está ligado à narrativa. Para ela a experiência é tanto o ensaiar, o pôr à prova, o testar, quanto a provação que permitem uma melhor compreensão das coisas.

Jerome Kohn agrupa os seus três ensaios de abertura dos Hannah Arendt papers, que estão na Divisão de Manuscritos da Biblioteca do Congresso dos Es- 
tados Unidos, sob o título "The role of experience in Hannah Arendt's political thought" ["O papel da experiência no pensamento político de Hannah Arendt"]. Ele menciona uma carta de 1946 a Jaspers, na qual ela fala da "infinitely complex red-tape existence of stateless persons". ${ }^{2}$ Essa experiência, somada ao texto de 1943 sobre a provação dos refugiados - "We refugees" (Arendt, 1978a, p.55-66) -, é um componente forte da reflexão arendtiana sobre os direitos humanos e sobre o conceito do direito a ter direitos elaborado em Origens do totalitarismo (Arendt, 2004, p.341-84 [1989, p.300-36]) - conceito que desenvolvi e trabalhei em $A$ reconstrução dos direitos humanos - um diálogo com o pensamento de Hannah Arendt (Lafer, 1988 e 1994). Em síntese, como ela diz no prefácio a Entre o passado e o futuro: "my assumption is that thought itself arises out of incidents of living experience and must remain bound to them as the only guide-posts by which to take its bearings"(Arendt, 1968a, p.14 [1972, p.41]).

Experiência, narrativa e pensamento estão indissoluvelmente interligados em Hannah Arendt, que entende, como já apontado, que as teorias, por mais abstratas que sejam ou pareçam, têm atrás de si estórias e incidentes que contêm in nuce o que temos a dizer. Não é assim, por acaso, que ela apreciava Maquiavel, Montesquieu, Tocqueville, os "founding fathers" da Revolução Americana - pensadores que escreveram com pertinência - de "dentro" e não de "fora" - sobre a política a partir da perspectiva das suas próprias experiências. É o que, com muita propriedade, aponta Bhikhu Parekh (1981, p.13-4), lastreado nas notas das aulas do curso de graduação dado por Hannah Arendt em Cornell - "Lectures on Machiavelli to Marx" ["Lições: de Maquiavel a Marx"] - no semestre de outono de 1965, parte dos quais assisti como ouvinte.

No prefácio que preparou para a cuidadosa edição de Rabel Varnhagen, diz Liliane Weissberg (Arendt, 1997, p.21):

For Arendt, political experience can only be mentioned if it is remembered and communicated because only in this way can meaning emerge. Remembering and communicating, this special form of Andenken that is looking back as well as a birth of something new, is at the core of storytelling. Stories recall experience and give birth to thought. (grifos meus)

Na obra de Hannah Arendt, regra geral, a experiência e a estória que instigam o pensamento estão subjacentes e mencionadas apenas ocasionalmente, como ela mesma diz no prefácio a Entre o passado e o futuro (Arendt, 1968a, p.14 [1972, p.41]). Também cabe lembrar que, se gostava de contar estórias, como aponta Elizabeth Young-Bruehl (1977, p.183-90) e elaborou os perfis recolhidos em Homens em tempos sombrios, ela só escreveu uma biografia, a de Rahel Varnhagen. Os cursos universitários que proferiu seguem a mesma linha de sua obra na qual a experiência e a estória que dela resultou estão subjacentes ao pensamento teórico que ensejaram. Há, no entanto, uma importante exceção. Refiro-me ao curso de pós-graduação por ela dado no Fall Term de 1965 na Universidade de Cornell, intitulado "Political experiences in the twentieth 
century" ["Experiências políticas no século XX"] do qual tive o privilégio de participar como seu aluno e cujas características e impacto descrevi em 1979 em texto que abria o meu primeiro livro dedicado ao seu pensamento (Lafer, 2003, p.15-21).

O meu texto é uma narrativa do que foi a experiência única de ouvir de viva voz o sopro do pensamento de Hannah Arendt, vale dizer, a de me dar conta do significado da metáfora socrática do vento, de que se valeu Hannah Arendt (1978b, p.174 [1992, p.131]) ao tratar da atividade do pensar. Por isso mesmo, parece-me apropriado retornar à experiência intelectual desse curso, num ensaio voltado para celebrar o centenário do seu nascimento, ocorrido em outubro de 2006.

\section{II}

O curso de Cornell tem um antecedente: o que deu em nível de graduação no Spring Term de 1955, na Universidade da Califórnia em Berkeley, intitulado "Contemporary issues"; e um desdobramento posterior: o curso de pós-graduação do Spring Term de 1968 na New School for Social Research, que tem exatamente o mesmo título do curso de Cornell. A interconexão dos três cursos, e muito especialmente dos dois últimos, é grande. É o que tive a ocasião de verificar ao consultar os roteiros de aula que preparou para esses cursos, nos quais se valeu das notas de Berkeley para o curso de Cornell e da New School, e das do curso de Cornell para o curso da New School. Essas notas/roteiros estão arquivadas nos seus papéis, abrigados na Manuscript Division da Biblioteca do Congresso dos Estados Unidos: o curso de Cornell, na parte referente ao subject-file 1949-1975 de cursos, no contêiner n. 57; os cursos de Berkeley e da New School, no contêiner n. 58. É a relevância desses cursos, em especial o de Cornell, a que assisti, e o da New School, que se lhe seguiu, que vou discutir na perspectiva do inter-relacionamento de experiência, estória, ação e pensamento na reflexão de Hannah Arendt, lastreado na pesquisa que logrei fazer em janeiro/fevereiro de 2006 na Biblioteca do Congresso dos Estados Unidos.

Acho interessante mencionar que Jerome Kohn e Elisabeth Young-Bruehl assistiram, como alunos, ao curso da New School. Jerome foi posteriormente assistente de Hannah Arendt na New School e tem se notabilizado não só como um arguto estudioso da obra arendtiana, mas também como um criterioso editor de ensaios dispersos e inéditos da grande pensadora. É, assim, um dos zelosos e dedicados defensores do legado intelectual de Hannah Arendt. Elisabeth Young-Bruehl é a autora da primeira, e por todos os títulos admirável, biografia de Hannah Arendt e acaba de publicar o livro Why Hannah Arendt Matters. Ambos, como relata Jerome Kohn, foram, como eu, impactados pela experiência única de ouvir de viva voz o pensamento de Hannah Arendt no curso sobre "Experiências políticas no século XX" (Kohn \& Young-Bruehl, 2006, p.220-2; Young-Bruehl, 2006) - o que indica uma compartilhada e duradoura dimensão de instigação heurística do sopro do seu pensamento. 


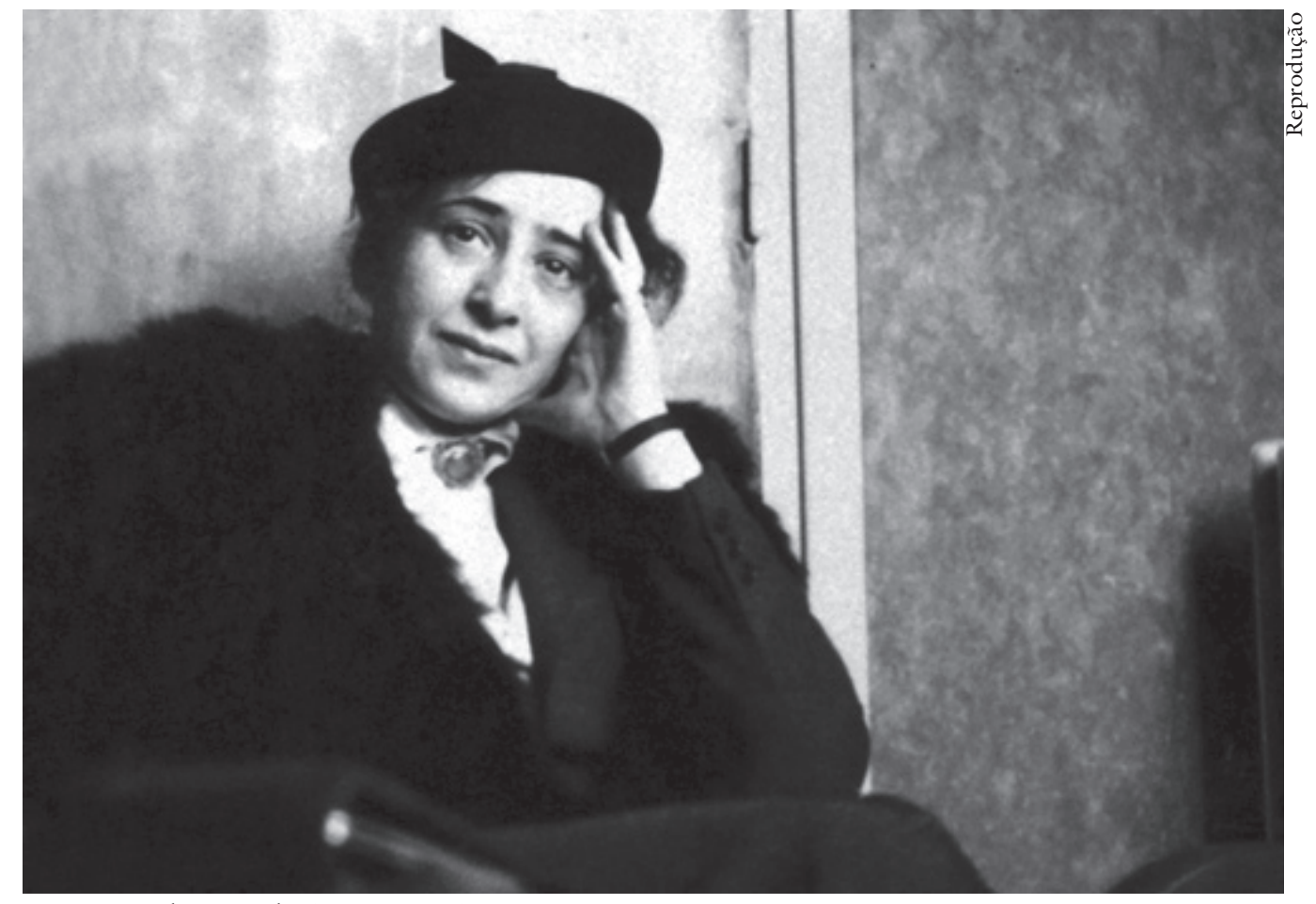

Hannah Arendt (1906-1975).

III

Os três cursos tratam das experiências políticas do século XX por meio da biografia imaginária de alguém que nasceu na última década do século XIX. A estória desse homem não é a de alguém que está à margem das coisas, apenas observando, mas não é, também, a de um grande ator protagônico - "though he will act occasionally as it were", como ela registra nas notas do curso da New School (contêiner n. 58 - 023611). A estória a ser narrada, portanto, não é a de alguém que esteve na política, ou seja, a de um grande protagonista "who made it" - como, observo eu, Churchill ou De Gaulle. Isso se explica porque Hannah Arendt nunca separou aqueles que sofrem a História daqueles que a fazem, como apontou Paul Ricoeur (1985, p.342). Cabe ao historiador, como ela afirmará posteriormente em $A$ vida do espírito, à maneira de Heródoto, "inquirir para poder dizer como foi" e a medida do juízo não é o hegeliano êxito histórico-político. Daí o apreço que tem nas suas empreitadas narrativas pelo ensinamento de Catão: "Victrix causa deis placuit sed victa Catoni" (Arendt, 1978b, p.216 [1992, p.163]). Por isso, por exemplo, escreveu sobre Rosa Luxemburg em Homens em tempos sombrios, e não sobre Lenin.

No curso, o que ela se propôs assim resgatar foi a experiência de alguém que reagiu aos eventos que sobre ele incidiram. É a perspectiva "of the man upon whom the events were raining as it were" e para quem - o que nem sempre acontece - a política determina o destino, como ela registra nas notas do curso de Cornell (contêiner n. 57 - 023761) - e que foi, aliás, o que sucedeu com ela própria em razão da ascensão do nazismo. 
É interessante registrar que essa imagem de chuva e destino evoca e reverbera o prefácio de Hannah Arendt à sua biografia de Rahel Varnhagen. Diz Hannah Arendt (1997, p.81 [1994, p.11]) que o empenho dessa ao procurar formular o significado do seu destino "was to expose herself to life so that it could strike her 'like a storm without an umbrella' ('What am I doing? Nothing. I am letting life rain upon me')".

O objetivo epistemológico dessa biografia imaginária era, para Hannah Arendt, discutir em que medida as teorias contemporâneas refletem ou são adequadas para lidar com as experiências políticas centrais do século XX (contêiner n. 57 - 023764). Essa discussão diz respeito a um tema relevante e recorrente de seu percurso: o da ruptura e da inadequação do conhecimento tradicional para dar conta do ineditismo que caracterizou o século XX. Por isso, o curso pode ser considerado um exemplo do que ela, no simpósio de 1972 sobre a sua obra, qualificou como "thinking without a bannister", vale dizer, sem o apoio do corrimão de conceitos seguros (Hill, 1979, p.336-7).

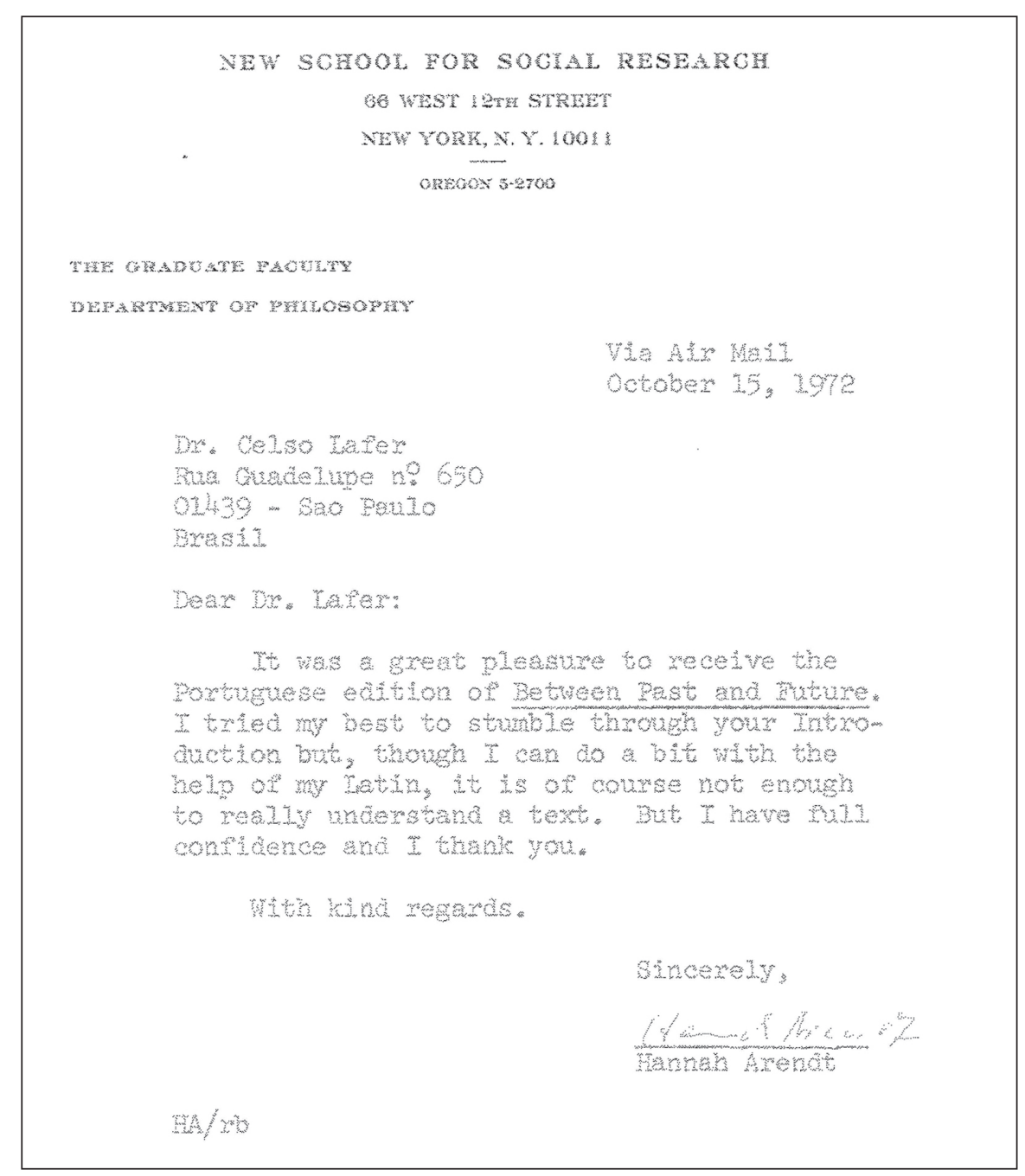


$\mathrm{Na}$ linha do seu ensaio em Entre o passado e o futuro, Hannah Arendt (1968a, p.57 [1972, p.88]) retomou no curso Vico e a sua concepção da História como algo capaz de ser conhecido pelos homens, porque feito pelos homens, observando, no entanto, que todas as filosofias da História falam de algo que não é feito por eles:

Adam Smith speaks of the invisible hand, Kant of the ruse of nature, Hegel of the cunning of Reasoning all of which work behind man's back. Nietzsche about Action. We don't know the motives, the origins, we don't know the end - has action any sense at all? (contêiner n. 57 - 02376l)

Nas notas do curso da New School, que ampliam as do curso de Cornell, indaga: "If history is not made by acting men, is it made by the historian?". A propósito, faz uma referência crítica a Collingwood, menciona Oakeshott e cita E. C. Carr, todos igualmente evocados no curso de Cornell. A citação de Carr trata da relação do historiador com os fatos, captados como quem pesca num grande oceano. Essa pesca, diz Carr, depende em parte do acaso, em parte da região do oceano que o historiador escolhe pescar, ou seja, do tipo de peixe no qual está interessado.

Pondera Hannah Arendt, em continuação, inserindo a idéia da narratividade, que há uma outra maneira de escrever história:

the original way of telling a story. The meaning of such stories is different from the grandiose meanings of which the historian speaks; it is not a pattern and hence can hardly be caught in one sentence. We think here of a lifestory, a biography. Of what a man could or would tell when he were to tell his story, and how he would distill, as it were, its essence. (contêiner n. 58 - 023611)

Elizabeth Young-Bruehl diz que a pessoa que Hannah Arendt tinha em mente ao conceber essa biografia imaginária era Heinrich Blücher, seu segundo marido e parceiro de reflexões - como atesta a correspondência de ambos (Arendt \& Blücher, 1996) -, pois a sua vivência do século XX tinha o lastro de experiências relevantes (Young-Bruehl, 1982, p.420 [1997, p.368]).

No curso de Cornell, a referência insinuada era Malraux, cujo livro, $A$ condição humana, na tradução para o inglês, Man's fate, estava na bibliografia e foi objeto de muita discussão e comentários no correr do semestre. Nas notas do curso de Cornell que foram aproveitadas no da New School, há apontamentos de Hannah Arendt sobre os personagens de Man's fate e sobre o significado político da estória narrada nesse romance (contêiner n. 58 - 023586, 023587). $\mathrm{Na}$ parte geral da bibliografia do curso de Cornell e da New School, ela incluiu significativamente as Anti-memoires [Antimemórias] de Malraux (contêiner n. $57-023751$, contêiner n. $58-023612$ ). É curioso, nesse sentido, apontar que, tratando de como Malraux lidou com a memória, Jean-Louis Jeanelle (2006, p.254-5) tenha feito referência a Hannah Arendt e à conjugação da praxis e da lexis no espaço público como elementos identificadores da ação e diferenciadores da atividade do homo laborans e do homo faber. 
No curso de Cornell, muito à sua maneira de refletir, faz uma distinção entre teoria e pensamento. Diz que todo evento que é lembrado é pensado. O contar de uma estória é uma forma apropriada de pensá-la. É daí que provém a teoria. A teoria feita no presente é como todo presente: tempo entre o passado e o futuro, isto é, entre lembrança e antecipação. Recorda a parábola de Kafka - que discute amplamente no prefácio de Entre o passado e o presente - das duas forças opostas que agem sobre o homem e a partir das quais ele pensa e age. Isso, diz ela, não é teoria, mas é certamente a determinação da localização das teorias (contêiner n. 57 - 023762).

É essa localização do pensamento, que não é ainda teoria, o que ela busca por meio da biografia imaginária proposta no curso, e, para captar o inter-relacionamento estória, experiência, pensamento, que fundamenta a sua proposta, realça a relevância da ficção. Disse a seus alunos que iriam ler "a lot of fiction in order to get the experience not in the raw but without theoretical overtones" (contêiner n. $57-023764)$. Nesse sentido, a propósito da experiência elaborada sem o tom da teoria, cabe lembrar como Hannah Arendt se valeu dos romances de Disraeli ou de Em busca do tempo perdido de Proust para pensar o anti-semitismo, ou da ficção de Joseph Conrad para pensar o imperialismo em Origens do totalitarismo, ou ainda do Bill Budd de Melville para discutir, em Sobre a revolução, o bem além da vontade e o mal além do vício.

A bibliografia do curso incluía, como era usual na sua obra e em especial em Origens do totalitarismo, além de romances, poesias, autobiografias, biografias, textos de cartas, transcrições de processos. Foram selecionados para esclarecer o concreto dos eventos a serem estudados no curso. $\mathrm{O}$ critério de seleção não era, no entanto, para recorrer à imagem de E. C. Carr, a pesca de peixes. Era (penso no seu grande ensaio sobre Walter Benjamin) o mergulho do pescador de pérolas que busca extrair das profundezas e trazer para a superfície o contorno das cristalizações que instigam o pensamento (Arendt, 1968b, p.193-206 [1987, p.165-76]; Benhabib, 1994, p.124-6), unificando-as por meio de uma biografia imaginária de alguém que viveu as experiências políticas do século XX.

Essas experiências foram, para o curso de Cornell, as seguintes: a Primeira Guerra Mundial; o pós-Primeira Guerra Mundial; a Guerra Civil Espanhola; a Rússia comunista; a Alemanha nazista; a Segunda Guerra Mundial; o segundo pós-guerra; e, finalmente, dois julgamentos do segundo pós-guerra: o caso $\mathrm{Al}$ ger Hiss (que lidava com o macartismo nos Estados Unidos) e o caso Oppenheimer (que tratava da responsabilidade dos cientistas diante da bomba atômica) (contêiner n. 57 - 023751, 023752). No curso antecedente de 1955 de Berkeley, a lista era a seguinte: a experiência da Primeira Guerra Mundial e do imediato pós-guerra; o espírito da Revolução; totalitarismo; a Segunda Guerra Mundial e a Resistência; e, como fecho, o mundo contemporâneo, subdividido em três itens: seu caráter global, sua dimensão de sociedade de massa, ciência e política (contêiner n. 58 - 024162). No curso de 1968, na New School, a lista foi: a Primeira 
Guerra Mundial; o pós-Primeira Guerra Mundial no Ocidente; o pós-Primeira Guerra e a Revolução; em busca da Revolução; conseqüências da Revolução; e, como fecho, a Segunda Guerra Mundial tratada em quatro subitens: a guerra propriamente dita, a Resistência, as fábricas da morte e Hiroshima (contêiner n. 58 -023612, 023613). Esses foram, assim, usando o seu linguajar, os guide-posts escolhidos para traçar a biografia imaginária de alguém cuja estória seria uma maneira de compreender o "perfil do século XX", para lembrar um título de um livro de Bobbio (1986) - seu contemporâneo - que também, à sua maneira, buscou, a partir da experiência italiana, o entendimento do que foi o século que ambos viveram.

\section{V}

O desafio de elaborar essa biografia imaginária não era pequeno, pois tratava-se de reviver, para narrar, os eventos do século XX e as experiências dele provenientes, no lugar do outro - "vicariously", como disse Hannah Arendt aos seus alunos no curso da New School. Com efeito, as experiências lastreadoras da lembrança dessa biografia, disse ela, "are not ours, perhaps partly mine, certainly none is yours". Daí a exigência da capacidade mental da imaginação, e por isso a proposta do curso foi a de "exercises in imagination" (contêiner n. 58 $-023609)$.

A palavra exercício designa atividade, provém do verbo latino exerceve, por sua vez derivado de ex, e de arcere, encerrar, donde a acepção "pôr para fora de um recinto cercado", registrado por Skeat no seu consagrado dicionário etimológico da língua inglesa. Em Entre o passado e o futuro, Hannah Arendt (1968a, p.15 [1972, p.41]) se propôs, por meio do que qualificou de "exercises in political thought", resgatar as origens de conceitos-chave da linguagem política - como liberdade e autoridade - para "distill from them anew their original spirit”, uma vez que tinham, por conta da ruptura, se convertido no recinto cercado de "empty shells". No curso, ela se propôs um exercício semelhante por meio de uma biografia imaginária, cabendo registrar que no prefácio de Entre o passado e o futuro - que data de 1961 - menciona a possibilidade de se escrever a história intelectual do século XX na forma de biografia de uma só pessoa. Essa hipotética biografia seria uma aproximação metafórica da consciência de uma pessoa que escapou do pensamento para a ação e que depois de ter agido se viu impelida a retornar ao pensamento (ibidem, p.9 [1972, p.35]).

Hannah Arendt observou nas notas do seu curso na New School que o meio de se elaborar essa biografia é a imaginação, cuja característica básica é "tornar presente o que está ausente", e dá destaque, para os propósitos do curso, à imaginação reprodutiva. Nesse âmbito, o seu interesse não é a lembrança simples e literal - por exemplo, a de uma ponte como a George Washington Bridge em Nova York. É a imaginação que enseja "to make present what was not given in any kind of perception but is mediated” (contêiner n. 58 - 023609). Daí, aliás, a já mencionada relevância da criação literária no conjunto do narrar arendtiano do 
século XX e a seleção de romancistas que, por meio de sua ficção, são observadores da ação histórica, ou então de poetas cujos versos condensam a sabedoria de "estórias" de experiência significativa, como aponta Julia Kristeva (2001, p.33).

Assim, no curso de Cornell, para discutir a Primeira Guerra Mundial, ela indicou Storms of Steel de Ernst Jünger, A fable e o conto "Victory" de William Faulkner; para analisar o pós-Primeira Guerra, além de Man's Fate de Malraux, elencou A náusea de Sartre, The mint de T. E. Lawrence e uma seleção de poemas de Brecht; para o trato da Guerra Civil Espanhola apontou Por quem os sinos dobram, de Hemingway; no exame da Alemanha nazista estava presente o Dr. Fausto de Thomas Mann; na discussão da Segunda Guerra Mundial constavam a bibliografia Catch 22 de Joseph Heller e o Dr. Zhivago de Boris Pasternak; e, para a temática do pós-Segunda Guerra, apontou os poemas de René Char, recolhidos em Hypnos Waking, e A queda, de Albert Camus (contêiner n. 57 $-023751,023752$ ).

Hannah Arendt tinha muita sensibilidade para a literatura, e, na sua garimpagem de criações literárias voltada para a elaboração da biografia imaginária, escolheu textos do tipo mais reprodutivo da realidade no sentido amplo. Tinha, no entanto, clara noção de que não eram documentos, mas mediações da imaginação criativa. No trato dessas mediações buscou, à maneira da sua análise da metáfora em Walter Benjamin, tornar visível o invisível e fazer sensível o abstrato com o objetivo - como aponta Erich Heller (1977, p.147-59) que escreveu sobre Hannah Arendt como crítica literária de abrir caminho para o conhecimento de correspondências. Essas, ao desvendarem afinidades entre coisas aparentemente remotas, trazem à tona componentes significativos do novo das experiências políticas do século XX (Arendt, 1968b, p.165-8 [1987, p.143-46]).

No trato de relatos biográficos como o de George Orwell, Na pior em Paris e Londres, ou de Ilya Ehrenberg, Memoirs 1921-1941 [Memórias 1921-1941]; de biografias como a de Souvarine e a de Isaak Deutsher sobre Stalin, ou de Allan Bullock sobre Hitler; da transcriação de processos como os dos expurgos stalinistas da década de 1930, complementados pelo discurso de Kruschev sobre os crimes da era de Stalin; dos "hearings" norte-americanos sobre o caso Oppenheimer - para mencionar outras indicações bibliográficas do curso de Cornell -, Hannah Arendt procedeu de maneira análoga, atenta, evidentemente, à fatura própria desses textos: buscou tornar, para seus alunos, visível o invisível das correspondências, para esclarecer as experiências políticas do século XX.

Essas indicações bibliográficas tinham como objetivo trazer o sal da vida de múltiplas experiências para contextualizar livros de análise histórica, como o de Hajo Holborn, The political collapse of Europe [O colapso politico da Europa], ou de discussão estratégico-diplomática, como o de Raymond Aron, The century of total war [O século da guerra total], para possibilitar o exercício conjunto, na sala de aula, na forma de seminários, da imaginação voltada para a construção de uma narrativa esclarecedora do século XX. 
No meu texto de 1979 sobre o curso de Cornell, registrei como Hannah Arendt, ao comentar os textos e as exposições que fazíamos, esclarecia o significado e o lastro concreto de muitos dos temas recorrentes de sua obra. Entre eles: a imprevisibilidade e a criatividade da ação; o significado econômico e político do imperialismo europeu; as transformações sociais trazidas pela Primeira Guerra Mundial e a nova dimensão do coletivo que fizeram aflorar; a especificidade e a atração do fenômeno revolucionário; o apelo do socialismo; as frentes populares e a Guerra Civil Espanhola; os expurgos de Stalin; o nazismo; a polícia secreta, o inimigo objetivo e a propaganda nos regimes totalitários; a dissolução da plausibilidade do tecido social e político e a dimensão da contingência; o ineditismo dos campos de concentração e do holocausto; a situação dos cientistas diante das conseqüências da bomba atômica; o problema de um código ético para coisas novas na vida da humanidade.

No curso, como também relato no mesmo texto de 1979 (Lafer, 2003, p.178), foi aflorando o início de suas reflexões estimuladas pela guerra do Vietnã, mais tarde recolhidas em Crises da república, em especial facetas do que ela discutiu em Sobre a violência e "Lying in politics", nos quais dois temas clássicos da relação ética/política - a violência e a mentira - foram examinadas no contexto das especificidades do século XX (Arendt, 1972, p.1-47, 105-98 [1973, p.13-48, 93-169]). Em sala de aula e em conversas, ouvi algo da substância do que ela subseqüentemente publicou sobre Brecht e Heidegger. Nessas publicações apontou equívocos da relação entre os intelectuais e a política no século XX, seja na óptica da esquerda seja na da direita (Arendt, 1968b [1987, p.177-213]; 1974, p.307-20).

\section{VI}

Ao concluir este ensaio, observo que o empenho em compreender o ineditismo do que significou o totalitarismo no século XX, que colocou em questão as tradicionais categorias do pensamento, levou Hannah Arendt, com base na sua experiência, a associar esse problema da ruptura com as dificuldades epistemológicas do julgar. O ensaio de 1954, "Understanding and politics" [Compreensão e política], é a sua primeira aproximação nessa matéria (Arendt, 1994, p.307-27, 328-60, e p.XIX-XX [1993, p.39-53]).

Nos últimos anos de sua vida, deu seqüência a esse tema tratando do modus operandi do julgar, a partir de uma elaboração própria instigada pela Crítica do juizo de Kant, na qual - como se lê numa nota de 28 e 29 de abril de 1964 do seu Diário de pensamento - identificou elementos básicos para a questão do homem político (Arendt, 2005).

No curso de Cornell, isso já estava no seu horizonte. Com efeito, um dos tópicos possíveis do curso por ela proposto - que não foi o escolhido, pois manifestamos preferência pela biografia imaginária depois de agônica discussão entre muitas alternativas deslumbrantes - era "judging" como uma das faculdades envolvidas na vida política. Esse tema ela pretendia examinar com base na Crítica do juizo de Kant (contêiner n. 57 - 023763). 
O tema do julgar, embora não explicitamente trabalhado, estava latente no curso de Cornell e aparece com mais nitidez no da New School, como indica Wolfgang Heuer (2005, p.37-51). Ambos apontam, assim, para a direção que a reflexão arendtiana tomou nos últimos anos de sua vida - uma direção inconclusa, pois ela faleceu quando ia começar a redação de "O julgar" que complementaria "O pensar" e "O querer" do A vida do espirito. As indicações mais circunstanciadas que deixou são o pós-escrito de Thinking e o curso do Fall Semester de 1970 na New School, editado com um importante ensaio interpretativo de Ronald Beiner e publicado em $1982 \mathrm{com}$ o título Lições sobre a filosofia politica de Kant (Arendt, 1982 [1994]). ${ }^{3}$

Com base nessas indicações, pode-se dizer que o juízo, como uma faculdade distinta do pensar e do querer, no pluralismo do cogito arendtiano, é a capacidade de lidar com o particular sem perder o horizonte do seu significado geral. É uma habilidade política porque capacita o ator a se orientar no espaço público avaliando o que nele se passa. É indispensável na modalidade retrospectiva do espectador, para lastrear a compreensão do historiador. Requer, à maneira de Kant, um juízo de tipo reflexivo e não determinante, porque numa época de ruptura não é possível subsumir o específico a "universais" normativos esgarçados e fugidios. O juízo reflexivo sobre o particular, para se generalizar, requer o "tertium comparationis", e, para Hannah Arendt, o melhor caminho que Kant nos oferece é o da validade exemplar, que revela uma dimensão geral que de outra forma não poderia ser captada. A validade exemplar em Hannah Arendt não se cinge a objetos estéticos ou indivíduos que são paradigmas de certas virtudes, mas estende-se a eventos do passado que carregam um significado que vai além do mero acontecimento, como aponta Maurizio Passarin d'Entrèves (2000, p.251). São, assim, um apoio do juízo. Daí a importância da narratividade, pois ela se propôs, como observa Ronald Beiner, uma teoria política a partir de "estórias" e experiências, e não dos precários universais de leis gerais do processo histórico (Arendt, 1982). ${ }^{4}$

Os cursos de Berkeley, Cornell e da New School partem, como apontei, dos "guide posts" dos eventos por ela identificados como dotados de significado, que ela traz à tona com base na multiplicidade das experiências políticas do século XX e nas correspondências que desvendou a partir dos textos selecionados nas bibliografias. O objetivo foi alcançar um juízo retrospectivo sobre o perfil do século XX, por meio da validade exemplar de uma biografia imaginária. Essa ela foi ensaiando com seus alunos em sala de aula, valendo-se dos "exercises in imagination". Por isso os cursos de Cornell de 1965 e o da New School de 1968 antecipam concretamente o modus operandi do juízo tal como articulados nas Lições de 1970. Daí as indicações sobre a imaginação e o "sensus communis", como o senso de comunidade que enseja a mentalidade alargada, propiciadora do juízo reflexivo.

No curso da New School ela esclarece que a "enlarged mentality" kantiana significa: 
to think in the place of somebody else. The more people you are able to think in the place of, the more you will be able to re-present, to make present in your own person while they are absent. The virtue of the statesman called Insight. This is not empathy. You are not supposed to feel as they felt but to imagine through learning of their "feelings", thinking, etc. how you would have felt, thought, etc. You think your own thoughts but in the place of somebody else. Only if you think your own thoughts can you actually experience, though still in a mediated fashion-vicariously. (contêiner n. 58 - 023609)

Nessa passagem está o ponto de partida epistemológico do curso, complementado com as seguintes considerações sobre o modus operandi do juízo:

To exercise this kind of imagination is the condition for judgement. The enlargement of mentality permits you to take account the perspective of others as well as their circumstances. It means to judge from a perspective which is not your own. The world presents itself always to an enormous number of such perspectives; it is common to all of us precisely because each one of us sees it in a different perspective. (contêiner n. 58 - 023609)

Como ela disse subseqüentemente nas Lições de 1970: "To think with an enlarged mentality means that one trains one's imagination to go visiting" (compare the right to visit in Perpetual Peace [A paz perpétua]) (Arendt, 1982, p.43 [1994, p.45]).

O procedimento desse "sair em visita" está ligado à sua reflexão sobre o pensamento político como representativo, tal como ela formula no ensaio sobre "Verdade de política" de Entre o passado e o futuro, evocando a Crítica do juízo de Kant: "I form an opinion by considering a given issue from different view points, by making present to my mind the stand points of those who are absent; that is a represent them" (Arendt, 1968a, p.241 [1972, p.299]). Observa Leora Y. Bilsky (2001, p.271), comentando essa passagem, que em Hannah Arendt o juízo reflexivo é, assim, um juízo situado, que tem lugar num tempo humano e está inserto na perspectividade humana.

O tema da importância da multiplicidade de perspectivas e de suas circunstâncias aqui mencionadas - que curiosamente reverbera Ortega y Gasset - explica a escolha dos textos do curso e ao mesmo tempo fundamenta o perspectivismo de Hannah Arendt no mundo comum que as enseja. Nesse sentido, como diria Ortega, em Hannah Arendt a divergência de perspectivas não é contradição, mas complemento (Ortega y Gasset, 1958, p.96).

Observa Lisa Jane Disch (1996, p.13 e no cap.5) que a perspectiva de "sair em visita" não se confunde nem com o olhar de um ponto de vista de Arquimedes, em que o observador se afasta da terra, nem com o particularismo do testemunho que afirma a maneira pela qual alguém vê e experiencia o mundo. O "sair em visita" objetiva conversar com distintas perspectivas para considerar e ponderar como diferem da nossa própria perspectiva.

Hannah Arendt, na seqüência das suas notas, aponta os desafios para se alcançar a mentalidade alargada - ou seja, a de se conseguir imaginar a orteguiana 
complementaridade de perspectivas - que no mundo contemporâneo transcende as fronteiras nacionais, o que sempre foi, diz ela, uma experiência para o juízo em matéria de política externa. É por conta disso que a instigante narratividade da biografia imaginária, tecida no curso que com ela fiz, tem a característica dos signos em rotação de uma "obra aberta", na qual ela se empenha em encontrar o perfil do século XX na dispersão dos seus fragmentos.

Nas Lições, Hannah Arendt (1982, p.36, 43, 74 [1994, p.39, 45, 75]) observa que, para Kant, o que une a teoria à prática é o juízo. Ela também estabelece um liame entre a Crítica do juízo e o Projeto da paz perpétua na medida em que a hospitalidade universal instiga a extensão da mentalidade alargada. No curso da New School, ela indica as dificuldades desse "enormous enlargement of our 'enlarged mentality”" (contêiner n. 58 - 023609).

Faço este registro das dificuldades para finalizar com uma nota pessoal, baseado na minha experiência como ministro das Relações Exteriores do Brasil, no que tange ao desafio do juízo diplomático. O juízo diplomático, como um juízo político prospectivo, não pode se circunscrever ao "sensus privatus" do solipsismo da soberania. Requer, para orientar-se reflexivamente no mundo, avaliando o que nele se passa, o "sensus communis" que, no caso, é o senso de comunidade do mundo, sem o qual se incide, ou no risco de subestimar, ou no de sobreestimar o que um país representa para os demais. O primeiro risco leva à inércia e ao conformismo. O segundo, à inconseqüência ou à temeridade. Não é fácil ter esse senso para afastar esses dois riscos. Com efeito, vivemos num planeta heterogêneo em matéria de concepções e valores, mas unificado pelas forças centrípetas da revolução técnica, econômica e intelectual desencadeadas no século XX, cuja compreensão Hannah Arendt buscou na sua trajetória. Por isso é tão difícil, na formulação e execução do juízo diplomático, o enorme alargamento da mentalidade alargada requerido para orientar-se no mundo. Um orientar-se "without banisters" que precisa levar em conta, sem se perder, a complementaridade das perspectivas, na definição de posições da política externa.

\section{Notas}

1 Este ensaio é uma versão revista e ampliada de artigo publicado em espanhol na $R e$ vista de Occidente, n.305, p.78-98, octubre 2006. As indicações de datas e páginas das referências entre colchetes referem-se às edições brasileiras, listadas nas Referências bibliográficas do artigo.

2 Trata-se da carta de Hannah Arendt a Karl Jaspers, de 29 de janeiro de 1946 (cf. Arendt \& Jaspers, 1992, carta 34, p.28).

3 Tratei do juízo reflexivo arendtiano como caminho para a reconstrução dos direitos humanos no capítulo IX de A reconstrução dos direitos humanos (Lafer, 1988).

4 Cf. nota introdutória de Ronald Beiner ao texto do seminário sobre a Crítica do juizo, intitulado "Imagination" (p.79). 
Referências bibliográficas

ARENDT, H. Between past and future. New and enlarged edit. New York: Viking Press, 1968a.

. Men in dark times. New York: Harcourt, Brace and World, 1968b.

. Crisis of the republic. New York: Harcourt, Brace Jovanovich, 1972.

. Vies politiques. Paris: Gallimard, 1974.

1978a.

. The Jew as Pariah. Introduction by Ron Feldman. New York: Grove Press,

The life of the mind. New York: Harcourt, Brace, Jovanovich, 1978b. v.I, "Thinking", p.174.

. Lectures on Kant's Political Philosophy. Edited with an interpretative Essay by Ronald Beiner. Chicago: Chicago University Press, 1982.

Essays in understanding - 1930-1954. Edited by Jerome Kohn. New York: Harcourt Brace, 1994.

Rahel Varnhagen - The life of a Jewess. First complete edition, edited by Liliane Weissberg. Trans. Richard and Clare Winston. Baltimore: The Johns Hopkins Press, 1997.

. The human condition. 2.ed. Chicago: University of Chicago Press, 1998.

. The origins of the totalitarianism. New York: Schoken Books, 2004.

. Journal de pensée (v.2 - mars 1954-1973). Edité par Ursula Ludz e Ingeborg Nordmann. Traduit de l'allemand et de l'anglais par Sylvie Courtine - Denamy. Paris: Seuil, 2005 (Cahier sur Kant, p.1012, e posfácio das editoras, p.1039).

ARENDT, H.; BLÜCHER, H. Within Four Walls, The Correspondence between Hannah Arendt and Heinrich Blücher - 1936-1968. Edited with an introduction by Lotte Köhler. New York: Harcourt Inc., 1996.

ARENDT, H.; JASPERS, K. Correspondence 1926-1969. Edited by Lotte Köhler and Hans Saner. Trans. Robert and Rita Kimbel. New York: Harcourt, Brace, Jovanovich, 1992.

BENHABIB, S. Hannah Arendt and the redemptive power of narrative. In: HIRCHMAN, L. P.; HIRCHMAN, S. K. (Ed.) Hannah Arendt critical essays. Albany: State University of N. York Press, 1994. p.111-37.

BILSKY, L. Y. When actor and spectator meet in the courtroom. In: BEINER, R.; NEDELSKY, J. (Ed.) Judgement, imagination and politics - themes from Kant and Arendt. New York, Oxford: Lanham/Boulder, Rowman \& Littlefield Publishers, 2001. p.272.

BOBBIO, N. Profilo ideologico dell novecento italiano. Turim: Einaudi, 1986.

D'ENTRÈVES, M. P. Arendt's theory of judgement. In: VILLA, D. (Ed.) The Cambridge Companion to Hannah Arendt. Cambridge: Cambridge University Press, 2000. p.251.

DISCH, L. J. Hannah Arendt and the limits of philosophy. Ithaca: Cornell University Press, 1996.

HELLER, E. Hannah Arendt as a critic of literature. Social Research, v.44, n.1, p.147-59, Spring 1977. 
HEUER, W. La imaginación es el prerrequisito del comprender (Arendt): Sobre el puente entre pensamiento y el juzgamiento. Cadernos de Ética e Filosofia Política 7, São Paulo, Departamento de Filosofia da Universidade de São Paulo, p.37-51, 2005. Disponível em: $<$ www.fflch.usp.br/df/cefp>.

HILL, M. A. The fictions of mankind and the stories of men. In: Hannah Arendt: the recovery of the public world. New York: St. Martin's Press, 1979. p.275-300.

JEANELLE, J.-L. Malraux, mémoire et metamorphose. Paris: Gallimard, 2006.

KOHN, J.; YOUNG-BRUEHL, E. Hannah Arendt on action and violence with reference to Simone Weil and Rachel Bespaloff on Homer's Iliad. In: BENFEY, C.; REMMLER, K. Artists, intellectuals and World War II - The Pontigny Encounters at Mount Holyoke College, 1942-1944. Amherst/Boston: University of Massachusetts Press, 2006. p.2202.

KRISTEVA, J. Hannah Arendt, life is a narrative. Trans. Frank Collins. Toronto: University of Toronto Press, 2001.

LAFER, C. A reconstrução dos direitos humanos. São Paulo: Cia. das Letras, 1988.

. La reconstrucción de los derechos humanos - Un dialogo con el pensamiento de Hannah Arendt. México: Fondo de Cultura Económica, 1994.

. Hannah Arendt, pensamento, persuasão e poder. 2.ed. rev. e ampl. São Paulo: Paz e Terra, 2003.

ORTEGA Y GASSET, J. El tema de nuestro tiempo. 13.ed. Madrid: Revista de Occidente, 1958.

PAREKH, B. Hannah Arendt and the search for a new political philosophy. New Jersey: Humanities Press, 1981.

RICOEUR, P. Temps et récit 3. Le temps raconté. Paris: Seuil, 1985.

WEISSBERG, L. Hannah Arendt, Rahel Varnhagen, and the Writing of (Auto)biography, In: ARENDT, H. Rabel Varnhagen - The life of a Jewess. First complete edition, edited by Liliane Weissberg. Trans. Richard and Clare Winston. Baltimore: The Johns Hopkins Press, 1997. p.21.

YOUNG-BRUEHL, E. Hannah Arendt's storytelling. Social Research, v.44, n.1, p.18390, Spring 1977.

. Hannah Arendt, for love of the world. New Haven: Yale University Press, 1982. . Why Arendt Matters. New Haven: Yale University Press, 2006.

Edições brasileiras citadas

ARENDT, H. Entre o passado e o futuro. São Paulo: Perspectiva, 1972. . Crises da República. São Paulo: Perspectiva, 1973.

1981. A condição humana. Rio de Janeiro, São Paulo: Forense Universitária, Edusp, Homens em tempos sombrios. São Paulo: Cia. das Letras, 1987.

Origens do totalitarismo. São Paulo: Cia. das Letras, 1989. 
ARENDT, H. A vida do espirito - O pensar, O querer, O julgar. Rio de Janeiro: Relume-Dumará, Ed. UFRJ, 1992.

ARENDT, H. A dignidade da politica - ensaios e conferências. Rio de Janeiro: RelumeDumará, 1993.

. Rabel Varnbagen - A vida de uma judia alemã na época do Romantismo. Rio de Janeiro: Relume-Dumará, 1994.

. Lições sobre a filosofia política de Kant. 2.ed. revista e ampliada. Rio de Janeiro: Relume-Dumará, 1994.

YOUNG-BRUEHL, E. Hannah Arendt, por amor ao mundo. Rio de Janeiro: RelumeDumará, 1997.

RESUMO - O artigo examina o alcance intelectual do curso de pós-graduação ministrado por Hannah Arendt na Universidade de Cornell, nos Estados Unidos, no semestre do outono de 1965, intitulado "Political experiences in the twentieth century". Baseia-se nos meus próprios apontamentos como seu aluno em Cornell e nos roteiros preparados por Hannah Arendt para ministrar o curso, que estão guardados nos seus papéis na Biblioteca do Congresso dos Estados Unidos. Indica, com base na documentação contida na Biblioteca do Congresso, as convergências desse curso com o ministrado anteriormente, em 1955, na Universidade da Califórnia e, subseqüentemente, em 1968, na New School for Social Research. Explora como esses cursos contribuem para a compreensão da importância por ela atribuída, na sua obra, à experiência, à narração, à ação, à imaginação e ao juízo reflexivo, que são componentes da maior relevância na configuração da originalidade do percurso intelectual de Hannah Arendt e que dela fazem uma das grandes pensadoras do século XX.

PALAVRAS-CHAVE: Hannah Arendt, Experiência, Narração, Ação, Imaginação e juízo reflexivo.

ABSTRACT - The article examines the intellectual relevance of Hannah Arendt's graduate course, "Political Experiences of the Twentieth Century", given in the Fall of 1965 at Cornell University. The article draws on my notes taken as her student in this course and on her own notes prepared for the course that are in her papers in the Library of Congress. The article relates, on the basis of her papers in the Library of Congress, this course to a previous one offered in 1955 at the University of California and to a subsequent one in 1968 given at the New School for Social Research. The article explores how these courses are relevant for the understanding of the importance in Hannah Arendt's work of experience, narrative, action, imagination, reflective judgement, that are critical components of her originality as a major thinker of the $\mathrm{XX}^{\text {th }}$ century.

KEYWORDS: Hannah Arendt, Experience, Narrative, Action, Imagination and reflective judgement.

Celso Lafer é professor titular da Faculdade de Direito da Universidade de São Paulo. @-c_lafer@uol.com.br

Recebido em 20.3.2007 e aceito em 4.4.2007. 